\title{
GW23-e1011 TIME-DEPENDENT EFFECT OF IBUTILIDE ON RABBIT CARDIAC ELECTROPHYSIOLOGICAL CHARACTERISTICS
}

doi:10.1136/heartjnl-2012-302920a.209

${ }^{1}$ Ling Zhang, ${ }^{1}$ Yan-hong Ma, ${ }^{1}$ Hua Chen, ${ }^{1}$ Shang-lei Yang, ${ }^{1}$ Oi-na Zhou, ${ }^{2}$ Mei Ma,

${ }^{1}$ Yue-mei Hou. ${ }^{1}$ Department of Arrhythmia, the First Affiliated Hospital of Xinjiang Medical University; ${ }^{2}$ Xinjiang Key Laboratory for Medical Animal Model Research

Objectives To observe time-dependent effect of ibutilide on rabbit cardiac electrophysiological characteristics.

Methods 20 adult and healthy New Zealand rabbits were anesthetised and intubated with a tracheal tube. The cardiac electrophysiologic variables were measured before and after ibutilide infusion $(0$, $10,15,30,40,60,90,120,180,240 \mathrm{~min}$ ) at a dosage of $0.284 \mathrm{mg} /$ $\mathrm{kg}$. These variables included the RR, ERP, pR, pA, ORS, OT, AH, HV intervals.

\section{Results}

1. Ibutilide significantly prolonged the AERP $p<0$. 05) at basic drive cycle lengths of $150-220 \mathrm{~ms}$ and there was non-significantly decrease of rate-dependent effect of AERP ( $p>0.05$ ).

2. Ibutilide had the significant suppressing effect on the sinus heart rate. The peak response time was $90 \mathrm{~min}(\mathrm{RR}=272.36$ $\pm 9.43 \mathrm{~ms}$ ) and the heart rate recovered without drug administration.

3. The differences of $\mathrm{A}-\mathrm{H}$ interval and $\mathrm{H}-\mathrm{V}$ interval at sinus rhythm before and after the administration of ibutilide weren't significant (all $\mathrm{p}>0.05$ ). After injection of ibutilide, the PR, ORS, OT intervals were significantly prolonged after administration in $10 \mathrm{~min}$ to $240 \mathrm{~min}$, the peak response time was $90 \mathrm{~min}$.

4. ST-T segment was elevated after administration of ibutilide in $2 \mathrm{~min}$, resolved in $60 \mathrm{~min}$ and disappeared in $9 \mathrm{~h}$. 


\section{ABSTRACTS}

5. There were no significant arrhythmia by administration at a dosage of $0.287 \mathrm{mg} / \mathrm{kg}$. The rabbit developed the frequent occurrence of 